\title{
DESENVOLVIMENTO INICIAL DE GRAMADO SEMEADO COM Paspalum notatum FLÜGGE $^{1}$
}

\author{
Cleber Daniel de Goes Maciel², Jessica Tiemi Hama², João Igor de Souza ${ }^{2}$
}

\begin{abstract}
INITIAL VEGETATIVE DEVELOPMENT

OF Paspalum notatum FLÜGGE TURFGRASS

With the objective of evaluating the initial vegetative development of $P$. notatum turfgrass recently installed by sowing, an experiment was conducted in an area destined to the formation of a soccer field. The sowing process was accomplished by throwing $50 \mathrm{~kg}$ of seeds in $2,400 \mathrm{~m}^{2}$. Four treatments were represented by turfgrass seedlings evaluation at $30,45,60$, and 75 days after sowing (DAS), between March and May, 2007. Replications included ten sample points by period, randomly selected with the aid of hollow squares $\left(0.25 \mathrm{~m}^{2}\right)$. Results indicated medium increment for dry matter in the aerial part of plants $(67.4 \%, 73.8 \%$, and $34.3 \%$, respectively, at 45,60 , and $75 \mathrm{DAS})$. In relation to the number of leaves per plant, medium increment was verified for new leaves (3.6, 9.6, and 6.9, respectively, at 45,60 , and $75 \mathrm{DAS})$, as well as the appearance of a new tiller in turfgrass plants, every 15 days, from 30 to 75 DAS.
\end{abstract}

KEY-WORDS: Growth; Bahiagrass; seedlings.

Pesquisas mencionam os benefícios de gramados ao ambiente, com destaque para o ajustamento natural, confortável e seguro ao divertimento e prática de esportes (TPI 2002). A espécie Paspalum notatum Flügge é utilizada, no Brasil, em áreas residenciais, industriais, urbanas e em rodovias, sendo este multipropósito justificado pela alta rusticidade e resistência à seca, solos ácidos e de baixa fertilidade (Gurgel 2003).

A formação de gramados, a partir de sementes, é uma prática comum nos EUA e Europa, sendo, no Brasil, ainda bastante recente, mas que, quando bem conduzida, pode formar gramados perfeitos e de excelente qualidade, a custo muito inferior, quando comparado aos métodos de plantio com mudas ou tapetes. A implantação de área com Axonopus sp. e $P$. notatum por sementes, normalmente, apresenta

\section{RESUMO}

A fim de avaliar o desenvolvimento inicial de gramado semeado com a espécie $P$. notatum, recém-instalado por meio de semeadura, um experimento foi conduzido em área destinada à formação de um campo de futebol. A semeadura foi realizada a lanço, em $2.400 \mathrm{~m}^{2}$, utilizando-se $50 \mathrm{~kg}$ de sementes. Quatro tratamentos foram representados pela avaliação das plântulas do gramado, aos 30, 45, 60 e 75 dias após a semeadura (DAS), entre março e maio de 2007. As repetições foram dez pontos amostrais por época, escolhidos aleatoriamente, com auxílio de quadrados vazados $\left(0,25 \mathrm{~m}^{2}\right)$. Os resultados indicaram ter havido incremento médio da matéria seca na parte aérea das plantas de $67,4 \% ; 73,8 \%$; e $34,3 \%$, respectivamente, aos 45 , 60 e 75 DAS. Com relação ao número de folhas por planta, foi constatado incremento médio de novas folhas de 3,6; 9,6; e 6,9, respectivamente, aos 45, 60 e 75 DAS, assim como o surgimento de novo afilho nas plantas do gramado, a cada 15 dias, entre 30 e 75 DAS.

PALAVRAS-CHAVE: Crescimento; grama batatais; plântulas.

germinação lenta (em torno de 60 dias), o que pode dificultar a formação de gramados de boa qualidade, principalmente devido à invasão de plantas daninhas e à falta de irrigação (Laurentti 2003).

Este trabalho teve como objetivo avaliar o desenvolvimento vegetativo inicial de grama mato-grosso ( $P$. notatum Flügge), em um campo de futebol formado a partir de sementes.

O experimento foi conduzido após semeadura a lanço, realizada em área de $40 \mathrm{~m}$ x $60 \mathrm{~m}$, em $16 / 02 / 2007$, através da distribuição superficial em solo classificado como Nitossolo Vermelho estruturado, com textura argilosa, utilizando-se $50 \mathrm{~kg}$ de semente, com $90 \%$ de pureza, $60 \%$ de germinação e valor cultural de $54 \%$.

As plântulas foram avaliadas aos 30, 45, 60 e 75 dias após a semeadura (DAS), entre os meses de

1. Trabalho recebido em dez./2009 e aceito para publicação em dez./2010 (n registro: PAT 8543/ DOI: 10.5216/pat.v40i4.8543).

2. Faculdades Integradas de Ourinhos, Departamento de Agronomia, Ourinhos, SP, Brasil.

E-mails: macielconsultoria@hotmail.com,jessicahama@yahoo.com.br,jigor_agronomia@yahoo.com.br. 
março e abril de 2007. Foram avaliados dez pontos amostrais por época, escolhidos aleatoriamente, a cada dez metros lineares, com auxílio de quadrados vazados de madeira, com área interna de $0,25 \mathrm{~m}^{2}$, totalizando área de $50 \mathrm{~m}^{2}$, de forma semelhante às metodologias descritas por Lara et al. (2003) e Maciel et al. (2008).

As amostragens foram realizadas através de coletas individualizadas de dez plântulas, em cada ponto de amostragem. Os parâmetros avaliados foram: número de folhas por planta, número de afilhos por planta e peso de matéria seca da parte aérea das plântulas. Os dados foram submetidos a análise de variância e, através de suas médias, foram estabelecidas curvas de regressão, conforme recomendações de Pimentel Gomes (1987) e Cousens (1988).

As temperaturas máximas e mínimas, assim como os níveis pluviométricos, apresentaram reduções progressivas de seus valores, a partir de maio (Tabela 1). Os valores médios de percentagem de incremento de matéria seca da parte aérea das plântulas da grama mato-grosso, ao longo das avaliações, foram de $67,4 \%, 73,8 \%$ e $34,3 \%$, respectivamente, aos 45 , 60 e 75 DAS (Figura 1). Entretanto, aos 75 DAS, foi caracterizada redução significativa do incremento da matéria seca da parte aérea do gramado, em relação aos demais períodos avaliados, tendo este efeito coincidido com o período de maior possibilidade de interferência de fatores ambientais, uma vez que os níveis de temperatura e disponibilidade hídrica apresentaram as maiores restrições no mês de maio (Tabela 1).

Com relação aos valores de frequência acumulada da matéria seca das plântulas de grama mato-grosso (Figura 2), pode-se observar maior desuniformidade no seu desenvolvimento aos 60 e 75 DAS, em relação às avaliações efetuadas aos 30 e 45 DAS. Este efeito pode ser justificado pela maior inclinação das

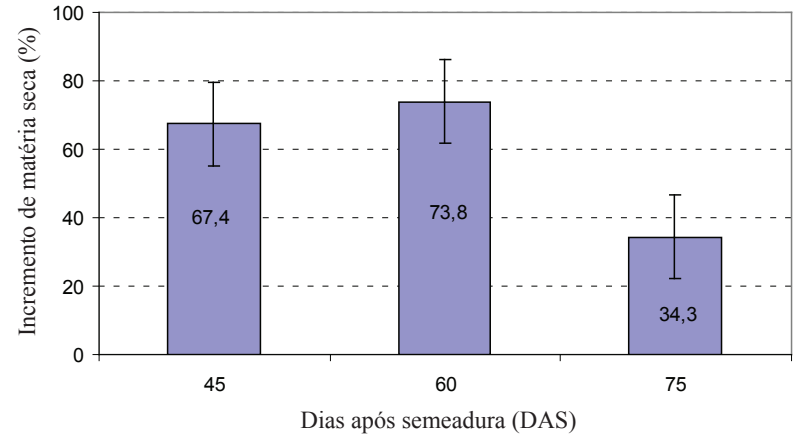

Figura 1. Incremento de matéria seca da parte aérea das plântulas de grama mato-grosso (Paspalum notatum Flügge), aos 45, 60 e 75 dias após a semeadura (Ourinhos, SP, 2007).

curvas de frequência acumulada de matéria seca da parte aérea das plântulas aos 60 e 75 DAS (Figura 2). Este resultado caracteriza a maior irregularidade no desenvolvimento de novas plântulas, entre as plantas já existentes no gramado, as quais se encontravam em pleno desenvolvimento vegetativo. Entretanto, a diferença entre o maior e o menor peso de matéria seca das plântulas encontradas nos levantamentos aos 30, 45, 60 e 75 DAS foi, respectivamente, representada pelos valores de $1,54 \% ; 10,72 \% ; 5,04 \%$; e $13,13 \%$. Desta forma, diferentemente das tendências das curvas, os resultados evidenciam as maiores discrepâncias na uniformidade da matéria seca das plantas, para as avaliações de 45 e 75 DAS.

Ainda assim, é importante ressaltar que, no desenvolvimento da grama mato-grosso, houve incremento progressivo em acúmulo de matéria seca das plântulas. Este incremento também pode ser demonstrado na Figura 2, onde, por exemplo, em 50\% das frequências acumuladas de matéria seca das plântulas coletadas aos 30, 45, 60 e 75 DAS, foram encontrados $0,0328 \mathrm{~g}$; $0,1446 \mathrm{~g} ; 0,5662 \mathrm{~g}$; e $0,8969 \mathrm{~g}$, respectivamente.

Tabela 1. Temperaturas máximas, mínimas e médias e pluviometria registradas durante a condução do experimento (Ourinhos, SP, 2007).

\begin{tabular}{|c|c|c|c|c|}
\hline \multirow{2}{*}{ Dias } & \multicolumn{3}{|c|}{ Temperaturas $\left({ }^{\circ} \mathrm{C}\right)$} & \multirow{2}{*}{$\frac{\text { Pluviometria }}{\left(\sum \mathrm{mm}\right)}$} \\
\hline & Mínimas & Máximas & Média & \\
\hline $\begin{array}{c}15 / 02 / 2007 \text { a } 15 / 03 / 2007 \\
\text { (30 DAS) }\end{array}$ & 34,7 & 19,0 & 26,9 & 148 \\
\hline $\begin{array}{c}16 / 03 / 2007 \text { a } 31 / 03 / 2007 \\
(45 \text { DAS })\end{array}$ & 35,4 & 17,8 & 26,6 & 67 \\
\hline $\begin{array}{c}01 / 04 / 2007 \text { a } 15 / 04 / 2007 \\
(60 \text { DAS })\end{array}$ & 35,5 & 17,8 & 26,6 & 13 \\
\hline $\begin{array}{c}16 / 04 / 2007 \text { a } 01 / 05 / 2007 \\
(75 \text { DAS) }\end{array}$ & 34,8 & 17,7 & 26,3 & 8 \\
\hline Total & 35,1 & 18,1 & 26,6 & 236 \\
\hline
\end{tabular}




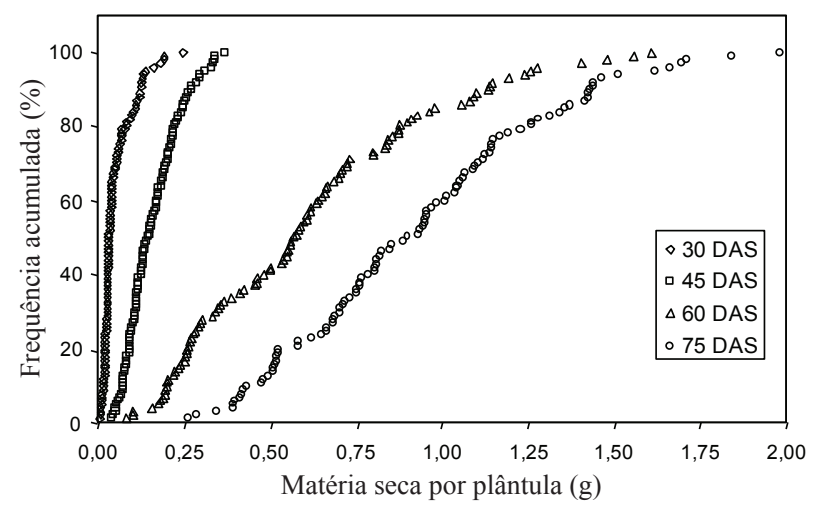

Figura 2. Dados originais da frequência acumulada (\%) de matéria seca da parte aérea de todas as plântulas de grama matogrosso (Paspalum notatum Flügge), avaliada aos 30, 45, 60 e 75 DAS (Ourinhos, SP, 2007).

Os valores médios de matéria seca das plântulas de grama aos 30, 45, 60 e 75 DAS foram ajustados ao modelo de regressão polinomial quadrático com elevada precisão $\left(\mathrm{R}^{2}=0,9774\right)$ (Figura 3$)$. Diferente dos ajustes adotados com relação aos parâmetros número de folhas por plântula e número de afilhos por plântula foi o modelo de regressão linear, o que, em ambos os casos, também confirmou alta precisão, apresentando os coeficientes de correlação $\left(\mathrm{R}^{2}\right)$ 0,9710 e 0,9999 , respectivamente.

Independentemente do ajuste dos modelos de regressão adotados para as características estudadas na grama mato-grosso, em gramado semeado no município de Ourinhos (SP), o crescimento inicial da espécie foi progressivo entre 30 e 75 DAS, período representado pelos meses de março a maio de 2007.

Pode-se concluir que a grama mato-grosso (P. notatum) apresentou desenvolvimento inicial favorável, entre os meses de março e maio, viabilizando a propagação por sementes para formação de gramados na região de Ourinhos (SP).

\section{REFERÊNCIAS}

COUSENS, R. Misinterpretations of results in weed research through inappropriate use of statistics. Weed Research, Oxford, v. 28, n. 4, p. 281-289, 1988.

GURGEL, R. G. A. Principais variedades e espécies de gramas. In: SIMPÓSIO SOBRE GRAMADOS, 1., 2003, Botucatu. Anais... Botucatu: Universidade Estadual Paulista, 2003. 1 CD-ROM.

LARA, J. F. R.; MACEDO, J. F.; BRANDÃO, M. Plantas daninhas em pastagens de várzeas no Estado de Minas Gerais. Planta Daninha, Viçosa, v. 21, n. 1, p. 11-20, 2003.
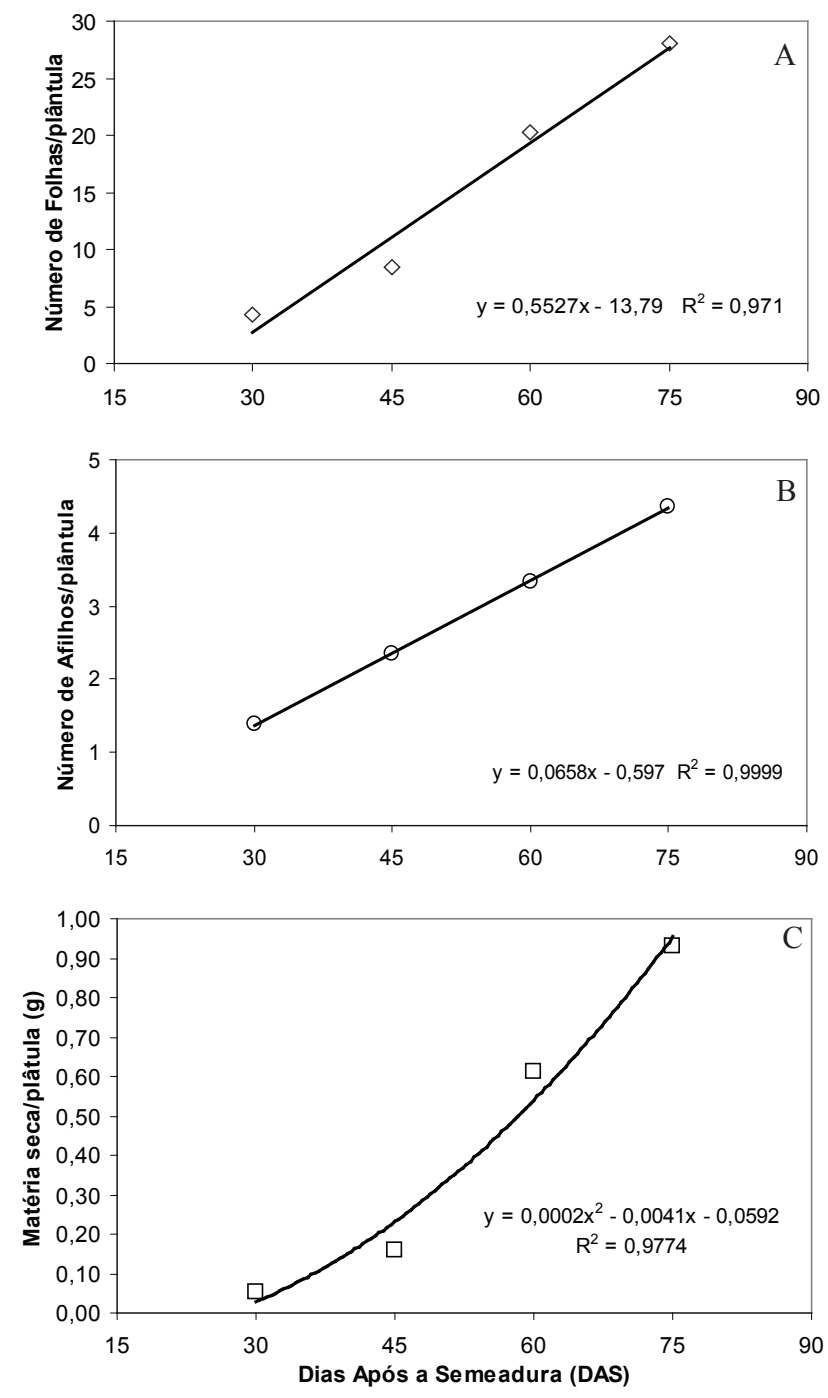

Figura 3. Número de folhas (A), número de afilhos (B) e matéria seca (C) por plântula, aos 30, 45, 60 e 75 DAS (Ourinhos, SP, 2007).

LAURENTTI, R. L. Implantação de gramados por sementes. In: SIMPÓSIO SOBRE GRAMADOS, 1., 2003, Botucatu. Anais... Botucatu: Universidade Estadual Paulista, 2003. 1 CD-ROM.

MACIEL, C. D. G. et al. Composição florística da comunidade infestante em gramados de Paspalum notatum no município de Assis, SP. Planta Daninha, Viçosa, v. 26, n. 1, p. 57-64, 2008.

PIMENTEL GOMES, F. A estatística moderna na pesquisa agropecuária. Piracicaba: Potafos, 1987.

TURFGRASS PRODUCERS INTERNATIONAL (TPI). Turfgrass: functional, recreational and aesthetic. 2002. Disponível em: $<\mathrm{http} / / \mathrm{www}$.turgrasssod.org/trc/ statistics. html>. Acesso em: 28 nov. 2002. 